\title{
BMJ Open Awareness and readiness to use telemonitoring to support diabetes care among care providers at teaching hospitals in Ethiopia: an institution- based cross-sectional study
}

\author{
Binyam Tariku Seboka (D) ,' Tesfahun Melese Yilma, ${ }^{2}$ Abraham Yeneneh Birhanu ${ }^{2}$
}

To cite: Seboka BT, Yilma TM, Birhanu AY. Awareness and readiness to use telemonitoring to support diabetes care among care providers at teaching hospitals in Ethiopia: an institution-based crosssectional study. BMJ Open 2021;11:e050812. doi:10.1136/ bmjopen-2021-050812

- Prepublication history and additional supplemental material for this paper are available online. To view these files, please visit the journal online (http://dx.doi.org/10.1136/ bmjopen-2021-050812).

Received 03 March 2021 Accepted 30 September 2021

Check for updates

(c) Author(s) (or their employer(s)) 2021. Re-use permitted under CC BY-NC. No commercial re-use. See rights and permissions. Published by BMJ.

${ }^{1}$ School of Public Health, Dilla University, Dilla, South Nations and Nationality region, Ethiopia ${ }^{2}$ Health Informatics, University of Gondar, Gondar, Amhara, Ethiopia

Correspondence to Mr Binyam Tariku Seboka; biniyamt@du.edu.et

\section{ABSTRACT}

Objectives This survey aimed to assess the awareness and readiness of healthcare providers to use telemonitoring (TM) technologies for managing diabetes patients as well as to identify associated factors in Ethiopia

Design An institution-based cross-sectional quantitative survey was conducted by using a pretested self-

administered questionnaire from February to March 2020. Data analysis used a binary logistic regression and partial proportional odds model for factor identification.

Participants Randomly selected 423 study physicians and nurses.

Setting This study was conducted at the University of Gondar and Tibebe Ghion specialised teaching referral hospitals.

Outcome measures Awareness and readiness towards $\mathrm{TM}$ in diabetes care.

Result Out of 406 healthcare providers $(69.7 \%, n=283$ nurses and $30.3 \%, n=123$ physicians) who completed the survey, 345 (38.7\%) heard about TM, when it came to readiness, $321(25.1 \%)$ and $121(65.5 \%)$ of respondents had average and low readiness towards TM, respectively. The result of regression analysis shows that awareness towards TM was higher among respondents who had access to a computer (adjusted OR (AOR): 2.8 (95\% Cl 1.1 to 7.1)), computer-related training (AOR: $4.6(95 \% \mathrm{Cl} 1.63$ to 12.95)) and those who had the experience of supporting patients through digital tools (AOR: $1.7(95 \% \mathrm{Cl} 1.0$ to 2.8)). Self-perceived innovators and those who had access to a computer, computer-related training and favourable attitude towards TM had significantly higher readiness to use TM.

Conclusion The findings of this survey revealed low awareness and readiness of participant's towards TM. However, this study suggests the need of improving participant's attitudes, access to smartphones and computers and technical skills to fill this gap.

\section{INTRODUCTION}

Digitising the health system is considered as a potential to improve healthcare services or possibly as an alternative in some healthcare areas such as chronic patient management. ${ }^{12}$

\section{STRENGTH AND LIMITATION OF THIS STUDY}

$\Rightarrow$ This is the first study to assess the awareness and readiness of Ethiopian healthcare providers to use telemonitoring technologies for supporting diabetes patients' management.

$\Rightarrow \mathrm{A}$ broad-based assessment on the measurement of a survey, including a pretest and the opinion of experts in the field.

$\Rightarrow$ Despite the collection of the questionnaire was done at the early stage of the COVID-19 pandemic, our survey has a high response rate among participants.

$\Rightarrow$ The cross-sectional nature of the study design prevents us to prove any causal relationship between the healthcare providers' awareness, readiness and the associated factors.

$\Rightarrow$ Since the study included only teaching hospitals, it may affect the generalisability of the findings to other healthcare settings.

According to American Telemedicine Association, telemonitoring (TM) is defined as 'the process of using audio, video and other telecommunications and electronic information processing technologies to monitor the health status of a patient from a distance'. ${ }^{34}$ These could enhance the care for a patient with diabetes mellitus (DM), which is a group of chronic metabolic disorders characterised by elevated blood glucose levels that are associated with significant morbidity, mortality and high healthcare cost. ${ }^{5}$ Over the past years, diabetes is becoming a public health problem in the world, affecting more than 463 million people in 2019. This global trend is also evident in Ethiopia, where more than 1.7 million people live with diabetes. ${ }^{78}$

Furthermore, in Ethiopia, patients with DM have a problem in controlling their blood glucose levels, the identified factors are inadequate home blood monitoring, non-adherence (non-compliance) with 
medications, poor lifestyle management (nutrition and physical activity) and suboptimal patient education about the disease and limited access to health professionals. ${ }^{9-11}$ In recent years, the application of different TM technologies emerges as an effective approach to solve the problems of patient education, ${ }^{12}{ }^{13}$ compliance,${ }^{14}$ monitoring of glucose levels and improving provider access ${ }^{15}$ and controlling diabetes complications. ${ }^{13}{ }^{16}$ Some interventional studies that are conducted in Bangladesh, Egypt and Senegal on diabetes patients have already shown this progresses. ${ }^{14} 1517$

However, to develop and implement strategies for using this technology, it is important to address factors related to the healthcare professional's readiness ${ }^{18} 19$ and awareness. There are possible deterrents discussed in the literature, which affect health professionals' awareness towards TM, including attitude towards Information Communication Technology (ICT), use of a computer and computerrelated training. ${ }^{20} 21$ In addition, individual factors such as gender, age, access to computers. ${ }^{20} 22{ }^{23}$ Behavioural factors like computer literacy, computer use and selfperceived innovativeness. ${ }^{20} 22$ 24-26 $\mathrm{TM}$ technology-related factors like perception towards privacy ${ }^{27}$ and security. ${ }^{2328} 29$ Organisational factors such as training, technical staff or support were found to affect the readiness of professionals. ${ }^{30-34}$

Despite the great promise of TM, to date, there is a lack of programmes to support diabetes or any chronic-related diseases through technology in Ethiopia. In this survey, TM solutions refer to remote internet or telephonebased monitoring of blood glucose, blood pressure and other signs and symptoms of diabetes patients and the recording devices are used by the patients in their home environment, and the generated data are transferred to healthcare providers over the internet, telephone or mobile phone. $^{2}$

The current survey aimed to determine the awareness and readiness to use TM technologies for managing diabetes patients and investigating factors influencing the awareness and readiness to support patients with TM technologies among healthcare providers in Ethiopia.

\section{METHODS}

\section{Study design and setting}

An institution-based cross-sectional study was conducted by using a quantitative approach in the Amhara region, Ethiopia from February to March 2020. The Amhara region is located in the North-Western and North Central parts of Ethiopia. It has 10 administrative zones, 1 special zone, 181 woredas and 78 urban centres. Amharic is the working language of the state. The capital city of the State of Amhara is Bahir-Dar. This study was conducted at specialised teaching hospitals in the Amhara Region, namely, the University of Gondar and Tibebe Ghion specialised teaching referral hospitals. Both hospitals are estimated to serve 5 million people in their catchment area, having a total of 1900 health professionals. Out of this number, 1029 of them were nurses and physicians working in those hospitals.

\section{Sample size and procedure}

The target population of this study was physicians and nurses from specialised teaching hospitals in the Amhara region and the sample size was determined based on the assumption of the single population proportion formula. Since there was no prior study undertaken on a similar study population, with an estimated precision of $5 \%$ and the $95 \%$ CI and a non-respondent rate of $10 \%$. Therefore, a sample of 423 physicians and nurses was taken.

All physicians and nurses who were working permanently (at least 6 months) in the respective hospitals were included in the study. Those who were on annual leave, sick leave, who left for a long time education during the data collection period were excluded from the study. The sampling method preferred for this study was simple random sampling. First, for each referral hospital, the proportional allocation of the participants was done. Then the participant was allocated proportionally to their respective departments. Finally, the participants were selected using a simple random sampling method from the respective departments. The full and detailed presentation of sampling procedure is provided as supplemental material (online supplemental file 1).

\section{Data collection instruments and preprocessing}

In this survey, a structured self-administered questionnaire was used to assess the awareness and readiness of health professionals towards TM. The design and development of the survey instrument were guided by the literature review and the questionnaire was adapted from various survey tools that had previously been pilot tested. ${ }^{18-20} 26 \quad 27$ The self-administered questionnaire consists of four sections. The first section includes sociodemographic and access to basic technical information of participants (10 items), the second section assessed behavioural factors (10 items), the third section included organisational and TM technology-related information (6 items), the final section of the questionnaire consisted of 1 item for awareness and 17 items for readiness assessment. The full questionnaire is provided as supplemental material (online supplemental file 2).

Participants' awareness of TM was assessed by a question to be answered in either 'yes' or 'no': aware if the participant answered 'yes' to the question and unaware of the participant answered 'no' to the question. ${ }^{20}$ The readiness of participants was assessed by using seventeen items rated on a 5-point Likert scale that ranged from ' $1=$ strongly disagree' to ' $5=$ strongly agree',. The result was interpreted in three levels of readiness: high, moderate and low level, those who scored above 81 points categorised as high readiness, those who scored between 61 and 80 categorised as moderate readiness, and those who scored below 0-60 categorised as low readiness. ${ }^{19} 2026$

In addition, a study was undertaken to assess the validity and reliability of the tools in our context, before the actual 
data collection, a pretest was carried out on 20 physicians and nurses who were working at Tikur-Anbesa specialised teaching hospital. Internal consistency was measured by Cronbach's alpha, with acceptable values of $(>0.7)$. The calculation for Cronbach's alpha in the pretest was set at 0.53 for core readiness, 0.84 for engagement readiness and 0.7 for the structural readiness construct.

Moreover, the opinions of two experts were taken related to the importance and relativity of the content based on the opinion and feedback gathered of experts and participants during the pretest. The investigator made adjustments to some declarations to clear their ambiguity, which was raised by pretest participants, instruction of questions number 4, 6 was changed from 'tick all that apply' to 'more than one answer is possible'. Furthermore, as a result of experts' opinion, adjustment was made on one item of the questionnaire to align the item with the research objective and improve its relativity to the content, from awareness section of the questionnaire item number 5 was changed from 'Have you ever used the following technology services (voice call, Simple Messaging Service (SMS), email, social media or video call) to support or monitor your patients?' to 'Do you have any experience with remote monitoring/supporting of patients via (eg, phone, SMS, email, social media, video call)?'.

Finally, we have used a paper-based self-administered version of the questionnaire during the data collection process, the distribution and gathering of a questionnaire were facilitated by using four data collectors and two supervisors, after giving 1 day of training on the purpose, objective and measurement of the survey. After the data collection, data were entered properly into Epi-data V.4.6 and exported to STATA V.14.1 for analysis. In addition to preventing data loss, electronic copies of data were stored and also shared with the Health informatics department, university of Gondar and advisors.

\section{Statistical analysis}

After the collection was done, the data were checked, cleaned, edited and analysed by using STATA V.14. Descriptive analyses (mean and percentage) were used to describe demographic characteristics and awareness and readiness levels of healthcare providers towards TM. The $\chi^{2}$ test was used to evaluate the statistical significance of the differences between the responses of the participants.

In our study, binary and ordinal logistic regression models were employed during factor analysis. The binary logistic regression method was used to identify independent variables associated with the awareness of participants. Ordinal logistic regression was used to identify factors associated with readiness, which is employed on ordered categories to estimate the cumulative probability of being in one category versus all lower or higher categories. The ordinal logistic regression model assumes that the distance between each category of outcome is equivalent (proportional), which is also known as the proportional odds (parallel lines) assumption. We have employed a Brant test to test whether the proportional odds assumption holds ${ }^{35}$ however, due to violation of the proportional odds assumption, the partial proportional odds model (PPOM) was fitted. OR was used to measure the association of outcome variables with predictor variables, $95 \% \mathrm{CI}$ and $\mathrm{p}$ value $(<0.05)$ were calculated to evaluate statistical significance.

\section{Operational definition}

Participants' core, engagement and structural readiness towards using TM were assessed. Core readiness (3 items, Cronbach's $\alpha=0.656$, range $3-15$ points) refers to the need for Tele-health services, dissatisfaction with the status quo and an expectation for change, engagement readiness (seven items, Cronbach's $\alpha=0.852$, range 7-35 points) refers to understanding as well as assessing the advantages and disadvantages of Telehealth service and Structural readiness ( 7 items, Cronbach's $\alpha=0.782$, range $7-35$ points) focused on technical infrastructure and staff skills. ${ }^{24}$ We defined overall readiness (17 items, Cronbach's $\alpha=0.876$, range $17-85$ points) as the intersection of core engagement and structural readiness. ${ }^{19}$

Nurses were defined as those employees with at least a diploma certificate in the nursing profession, and physicians in this study include general practitioners, internal medicine specialists and endocrinologists who are practicing clinical service in the study settings. ${ }^{30}$

\section{Patient and public involvement}

This study did not involve patients and the public.

\section{RESULTS}

From the 423 survey questionnaires distributed among physicians and nurses at the University of Gondar and Tibebe Ghion teaching hospitals, 406 (95.9\%) participants completed the survey questionnaire. The detailed demographic characteristics of participants were described previously. ${ }^{36}$ As described in detail previously, ${ }^{36}$ the majority of participants were men $(61.31 \%)$ and $57.6 \%$ of them were below the age of 30 years.

\section{Participants access to basic technologies}

As presented in table 1, the ownership and access to basic technologies varied according to participants characteristics. The ownership of electronic devices of computers and smartphones among men was $70.7 \%$ and $81.5 \%$, respectively. While only $44.3 \%$ stated they had internet access on their computers. Among participants below the age of 30 years, $69.2 \%$ own computers and $84.6 \%$ own smartphone devices (see table 1 for detail).

\section{Participant awareness for TM}

Regarding the awareness of physicians and nurses about TM, participants have shown low awareness in general. Only $38.7 \%$ (157/406) reported they had heard about telemonitoring. Even though there are slightly few respondents who are aware of TM technology, the majority $83.5 \%(339 / 406)$ of respondents are aware of 
Table 1 Sociodemographic characteristics and access to basic technologies at teaching hospitals in the Amhara region, Ethiopia, 2020.

\begin{tabular}{|c|c|c|c|c|c|c|c|}
\hline Variables & Categories & $\begin{array}{l}\text { Frequency } \\
(\%)\end{array}$ & $\begin{array}{l}\text { Own } \\
\text { computer }\end{array}$ & $\begin{array}{l}\text { Computer } \\
\text { with internet }\end{array}$ & $\begin{array}{l}\text { Own } \\
\text { smartphone }\end{array}$ & $\begin{array}{l}\text { Smartphone } \\
\text { with internet }\end{array}$ & $\begin{array}{l}\text { Social media } \\
\text { account }\end{array}$ \\
\hline \multirow[t]{2}{*}{ Gender } & Male & 249 & 70.7 & 44.3 & 81.5 & 94.1 & 85.9 \\
\hline & Female & 157 & 58.6 & 51.1 & 77.7 & 94.3 & 80.9 \\
\hline \multirow[t]{2}{*}{ Age } & $<30$ & 234 & 69.2 & 51.9 & 84.6 & 95.5 & 86.8 \\
\hline & $\geq 30$ & 172 & 61.6 & 38.7 & 73.8 & 92.2 & 80.2 \\
\hline \multirow[t]{5}{*}{$\begin{array}{l}\text { Educational } \\
\text { level }\end{array}$} & $\begin{array}{l}\text { Medical } \\
\text { doctor+ }\end{array}$ & 40 & 100.0 & 35.0 & 100.0 & 100.0 & 87.5 \\
\hline & $\begin{array}{l}\text { Medical } \\
\text { degree }\end{array}$ & 82 & 93.9 & 51.9 & 93.9 & 98.7 & 97.6 \\
\hline & $\begin{array}{l}\text { Master's } \\
\text { degree }\end{array}$ & 15 & 53.3 & 37.5 & 60.0 & 70.0 & 80.0 \\
\hline & Bachelor & 233 & 53.6 & 46.4 & 72.1 & 92.5 & 79.8 \\
\hline & Diploma & 36 & 50.0 & 55.6 & 86.1 & 94.2 & 77.8 \\
\hline \multirow{3}{*}{$\begin{array}{l}\text { Work } \\
\text { experience }\end{array}$} & $0-5$ & 145 & 72.2 & 50.0 & 84.6 & 97.1 & 88.8 \\
\hline & $6-10$ & 128 & 53.8 & 46.0 & 76.9 & 91.1 & 82.1 \\
\hline & $>10$ & 131 & 64.6 & 29.0 & 64.6 & 83.9 & 64.6 \\
\hline \multirow[t]{2}{*}{ Profession } & Physician & 123 & 95.1 & 46.2 & 95.1 & 99.1 & 93.5 \\
\hline & Nurse & 283 & 53.4 & 47.0 & 73.5 & 91.4 & 79.9 \\
\hline
\end{tabular}

the availability of self-management tools for diabetes patients. More than $88.5 \%(300 / 339)$ from $83.5 \%$ of respondents who are aware of self-management tools indicated that they recommend their patients to use different self-management tools.

As is seen in figure 1, regarding the specific selfmanagement tools that are recommended, respondents reported that the most commonly recommended selfmanagement tools were glucometer, 97.3\% (292/300), blood pressure measurement $78.3 \%(235 / 300)$, thermometer $39 \%(117 / 300)$, and only $17.3 \%(52 / 300)$ of them recommend mobile health applications.

The practice of using information technologies among physicians and nurses

A slim majority of $52.7 \%(214 / 406)$ of respondents are communicating with patients through either of the information technologies, phone calls, SMS, social media, email and video conference. The results also revealed

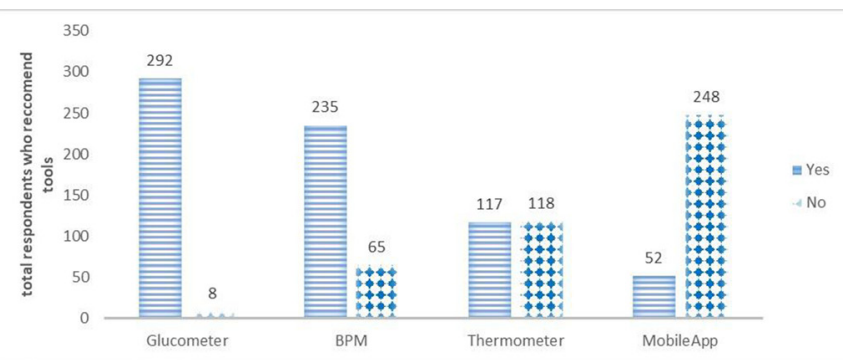

Figure 1 Most commonly recommended self-management tools by physicians and nurses at two teaching hospitals in Amhara region, 2020. that the highly used intercommunication method was voice calls, 96.7\% (207/214) while SMS, 59.8\% (128/214) (table 2).

\section{Participant readiness for TM}

Out of total participants, only $9.4 \%$ CI (6.7 to 12.3) of them have high readiness towards TM, $25.1 \%$ CI (20.1 to 29.6) of participants showed moderate or average readiness while a majority of participants $65.5 \%$ CI $(60.8$ to 70.4) shows low readiness level in this study.

Factors associated with physicians' and nurses' awareness of TM technology

Table 3 shows the details of bivariate and multivariate logistic regression, the results of logistic regression

Table 2 Frequency of using information technologies to support or consult patients among participants at teaching hospitals in Amhara region 2020.

\begin{tabular}{|c|c|c|c|}
\hline Tools & $\begin{array}{l}\text { Physician n } \\
(\%)\end{array}$ & $\begin{array}{l}\text { Nurse n } \\
(\%)\end{array}$ & $\begin{array}{l}\text { Total } \\
\left({ }^{*}\right)\end{array}$ \\
\hline $\begin{array}{l}\text { Mobile phone (voice } \\
\text { calls) }\end{array}$ & 81 (39.1) & $126(60.9)$ & 207 (96.7) \\
\hline $\begin{array}{l}\text { SMS (text } \\
\text { messaging) }\end{array}$ & $54(42.2)$ & 74 (57.8) & $128(59.8)$ \\
\hline Email & $3(12)$ & $22(88)$ & $25(11.6)$ \\
\hline Social media & 32 (49.2) & $33(50.8)$ & $65(30.3)$ \\
\hline Video conferencing & $4(57.1)$ & $3(42.9)$ & $7(3.27)$ \\
\hline
\end{tabular}

*Multiple response set, totals may sum up to more than $100 \%$. SMS, Simple Messaging Service. 
Table 3 Bivariate and multivariate logistic regression factors associated with awareness of TM technologies among physicians and nurses at teaching hospitals in the Amhara region 2020.

\begin{tabular}{|c|c|c|c|c|c|}
\hline \multirow[b]{2}{*}{ Variable } & \multirow[b]{2}{*}{ Category } & \multicolumn{2}{|c|}{ Awareness TM } & \multirow[b]{2}{*}{ Crude OR $(95 \% \mathrm{Cl})$} & \multirow[b]{2}{*}{ AOR (95\% Cl) } \\
\hline & & Yes n (\%) & No n (\%) & & \\
\hline Having a computer & Yes & $122(77.7)$ & $146(58.6)$ & $2.5(1.6 \text { to } 3.9)^{\star}$ & $1.8(0.9$ to 3.4$)$ \\
\hline \multirow[t]{2}{*}{ Computer training } & Yes & $70(44.6)$ & $69(27.7)$ & $2.1(1.4 \text { to } 3.2)^{*}$ & $1.8(1.0 \text { to } 3.2)^{\star}$ \\
\hline & No & $87(55.4)$ & $180(72.3)$ & 1 & \\
\hline Computer use & Never & $13(8.3)$ & 57 (22.9) & 1 & 1 \\
\hline \multirow{2}{*}{$\begin{array}{l}\text { Had the experience to support } \\
\text { patients using ICT tools }\end{array}$} & Yes & $96(61.1)$ & $118(47.4)$ & $1.8(1.2 \text { to } 2.6)^{\star \star}$ & $1.7(1.0 \text { to } 2.8)^{\star}$ \\
\hline & No & $61(38.9)$ & $131(52.6)$ & 1 & 1 \\
\hline $\begin{array}{l}\text { Downloading/uploading through the } \\
\text { internet }\end{array}$ & Daily & $65(41.4)$ & $99(39.8)$ & $2.4(1.9 \text { to } 6.3)^{*}$ & 1.1 (0.3 to 3.9$)$ \\
\hline Work experience & $>10$ years & $11(7.0)$ & $37(14.9)$ & 1 & 1 \\
\hline
\end{tabular}

analysis examined the association between awareness of $\mathrm{TM}$ and the independent variables (ie, own a personal computer, computer-related training, work experience, frequency of uploading and downloading the information through internet and experience in communicating with patients using information technology tools).

In the crude analysis, participants who owned a personal computer were about 2.5 times more likely to be aware of $\mathrm{TM}(\mathrm{OR}=2.5,95 \%$ CI 1.6 to 3.9$)$ as compared with those who did not own a personal computer. Likewise, participants who download/upload information daily were 2.4 times more likely to be aware of TM (OR=2.4, 95\% CI 1.9 to 6.3 ) as compared with those who never download or upload.

On the other hand, after adjusting the individual effect of the above confounders, participants who had computerrelated training (adjusted OR $(\mathrm{AOR})=1.8,95 \%$ CI 1.0 to 3.2) were more likely to be aware of TM as compared with participants who had no computer-related training. Similarly, participants who use computers daily were 2.8 times more aware likely to be aware of TM $(\mathrm{AOR}=2.8$, $95 \%$ CI 1.1 to 7.1 ) than those who did not use computers daily. Furthermore, participants who had experience in supporting/communicating patients using information technology tools were about 1.7 times more likely to be aware of (AOR=1.7, 95\% CI 1.0 to 2.8) as compared with participants who had no experience to support/communicate patients through information technology tools.

Factors associated with physicians' and nurses' readiness for TM technology using the ordinal logistic regression model

In this survey, ordinal logistic regression was conducted to examine the effect of predictor variables such as owning a computer, owned smartphone, computer-related training, Information Technology (IT) support, internet access, awareness, attitude towards ICT tools, perception towards data security of TM technologies and frequency of computer use on the readiness of participants. Table 4 shows the results of the ordinal logistic regression model. Even though five of the considered variables in the proportional odds model (POM) are found significant and the data satisfy the overall proportional odds assumption, the overall goodness of fit of the model shows a low $\mathrm{p}$ value.

Therefore, to fulfil the assumption of proportional odds, the Brant test was employed, after conducting the Brant test, $p$ values of 0.01 were found for the owned smartphone and computer-related training variables, indicating the two variables were found to violate the proportional odds assumption. The results of the Brant test are shown in the last column of table 4 . This reveals that all variables except having a smartphone and computerrelated training were found insignificant.

As a result, a PPOM was fitted. As is seen in table 5, the PPOM with logit function was fitted with variables that are changing across equations, while other variables were imposed to have their effects meet parallel-line assumption and the global Wald test for the final model indicates that the final model does not violate the proportional odds assumption.

Factors associated with physicians' and nurses' readiness for TM technology using a PPOM

In this survey, variables like owning a smartphone, attitude towards ICT tools in healthcare, attitude towards 
Table 4 Result of the proportional odds model for TM readiness among physicians and nurses at teaching hospitals, 2020.

\begin{tabular}{|c|c|c|c|c|c|}
\hline Variable & Coefficient & SE & P value & Odds ratio $(95 \% \mathrm{Cl})$ & $\begin{array}{l}\text { Brant test } \\
\text { p-value }\end{array}$ \\
\hline Intercept 1 & 3.748 & 0.644 & 0.000 & & \\
\hline Intercept 2 & 5.72 & 0.686 & 0.000 & & \\
\hline \multicolumn{6}{|c|}{ Having a computer (no as reference) } \\
\hline Yes & 0.462 & 0.4297 & 0.087 & 1.588 (0.934 to 2.699$)$ & 0.14 \\
\hline \multicolumn{5}{|c|}{ Use of computer at work (never as reference) } & 0.94 \\
\hline Weekly & -0.585 & 0.2162 & 0.132 & $0.5568(0.2601$ to 1.191$)$ & \\
\hline Daily & 0.130 & 0.4381 & 0.735 & 1.139 (0.5360 to 2.420$)$ & \\
\hline \multicolumn{6}{|c|}{ Having a smartphone (no as reference) } \\
\hline Yes & 0.259 & 0.4122 & 0.415 & 1.295 (0.6946 to 2.417$)$ & $0.01^{*}$ \\
\hline \multicolumn{6}{|c|}{ Computer-related training (no as reference) } \\
\hline Yes & 0.072 & 0.26602 & 0.768 & 1.075 (0.6623 to 1.746$)$ & $0.01^{*}$ \\
\hline \multicolumn{6}{|c|}{ IT-support (no as reference) } \\
\hline Yes & 0.462 & 0.42546 & 0.084 & 1.588 (0.9397 to 2.685$)$ & 0.27 \\
\hline \multicolumn{6}{|c|}{ Internet access (no as reference) } \\
\hline Yes & 0.299 & 0.3497 & 0.248 & 1.349 (0.8116 to 2.242$)$ & 0.23 \\
\hline \multicolumn{6}{|c|}{ Heard about tele-monitoring(no as reference) } \\
\hline Yes & 0.2499 & 0.3038 & 0.291 & 1.283 (0.8074 to 2.0418$)$ & 0.91 \\
\hline \multicolumn{6}{|c|}{ Attitude about ICT in current healthcare (bad as reference) } \\
\hline Good & 0.7911 & 0.5951 & 0.003 & $2.205(1.300$ to 3.7431$)$ & 0.75 \\
\hline \multicolumn{6}{|c|}{ Attitude about ICT in future healthcare (bad as reference) } \\
\hline Good & 0.7937 & 0.8325 & 0.035 & 2.211 (1.0575 to 4.625$)$ & 0.14 \\
\hline \multicolumn{6}{|c|}{ Attitude about ICT for remote monitoring (bad as reference) } \\
\hline Good & 1.189 & 1.036 & 0.000 & 3.285 (1.769 to 6.098$)$ & 0.78 \\
\hline \multicolumn{6}{|c|}{ Self-perceived innovativeness (not innovative as reference) } \\
\hline Innovative & 1.249 & 1.059 & 0.000 & $3.488(1.9228$ to 6.327$)$ & 0.73 \\
\hline
\end{tabular}

remote monitoring, and use of computers were positively associated with the readiness towards TM (table 5).

The result of PPOM revealed that participants who had a favourable attitude towards remote monitoring were about 3.5 times more likely to have high readiness for TM as compared with those participants with an unfavourable attitude. Similarly, participants who had a favourable attitude to healthcare ICT tools were about 2.4 times more likely to have high readiness than those participants with an unfavourable attitude.

In addition, when high readiness and average readiness compared with low readiness level, participants who used computers daily and weekly had 1.628 and 1.55 times greater odds of having average or high readiness, respectively, compared with participants who never used computers. Correspondingly, the odds of having high readiness for TM were 1.65 times higher for participants who perceived themselves as innovative as compared with those who did not perceive themselves as innovative.
Furthermore, the odds of having high readiness for TM were 1.65 times higher for the participants who owned personal computers as compared with those who did not own a personal computer.

\section{DISCUSSION}

To our knowledge, there is a lack of studies that have been conducted in Ethiopia to assess the awareness and readiness of health professionals for the implementation of e-health applications in inpatient care. This paper attempts to address this knowledge gap.

According to this analysis, about $38.7 \%$ of participants have heard about TM, which is a low level of awareness. This could be due to no specific courses are provided about telemedicine or TM for clinical staff and graduates of clinical fields have not been highly trained in this regard. This result was consistent with the study done in Saudi Arabia, 33\% heard about Tele-dentistry. ${ }^{27}$ However, 
Table 5 Result of partial proportional odds model for TM readiness among physicians and nurses at teaching hospitals, 2020.

\begin{tabular}{|c|c|c|c|c|c|c|}
\hline \multicolumn{7}{|c|}{ Comparisons } \\
\hline \multirow{2}{*}{ Variable } & \multicolumn{3}{|c|}{ Low readiness vs average and high readiness for TM } & \multicolumn{3}{|c|}{ Low readiness and average vs high readiness for TM } \\
\hline & B1 & OR1 & P value & B2 & OR2 & P value \\
\hline Coefficient & -3.9498 & - & 0.000 & -4.731 & & 0.000 \\
\hline \multicolumn{7}{|c|}{ Having a computer (no as reference) } \\
\hline Yes & 0.44887 & 1.64975 & 0.024 & 0.44887 & 1.64975 & 0.964 \\
\hline \multicolumn{7}{|c|}{ Use of computer at work (never as reference) } \\
\hline Weekly & 0.2160 & 1.5517 & 0.019 & 0.2160 & 1.5517 & 0.019 \\
\hline Daily & 0.4515 & 1.628 & 0.032 & 0.4515 & 1.628 & 0.032 \\
\hline \multicolumn{7}{|c|}{ Having a smartphone (no as reference) } \\
\hline Yes & 0.40962 & 1.2702 & 0.860 & 0.4096 & 1.2702 & 0.034 \\
\hline \multicolumn{7}{|c|}{ Computer related training (no as reference) } \\
\hline Yes & 0.3099 & 1.1658 & 0.543 & 0.15857 & 0.42433 & 0.102 \\
\hline \multicolumn{7}{|c|}{ IT-support (no as reference) } \\
\hline Yes & 0.4404 & 1.61857 & 0.062 & 0.4404 & 1.618557 & 0.383 \\
\hline \multicolumn{7}{|c|}{ Internet access (no as reference) } \\
\hline Yes & 0.34933 & 1.32788 & 0.413 & 0.34933 & 1.32788 & 0.296 \\
\hline \multicolumn{7}{|c|}{ Heard about Tele-monitoring (no as reference) } \\
\hline Yes & 0.3006 & 1.2575 & 0.338 & 0.3006 & 1.25754 & 0.49 \\
\hline \multicolumn{7}{|c|}{ Attitude about ICT in current healthcare (bad as reference) } \\
\hline Good & 0.6060 & 2.2276 & 0.003 & 1.7108 & 3.0627 & 0.045 \\
\hline \multicolumn{7}{|c|}{ Attitude about ICT in future healthcare (bad as reference) } \\
\hline Good & 0.90752 & 2.36617 & 0.025 & 0.9075 & 2.3661 & 0.025 \\
\hline \multicolumn{7}{|c|}{ Attitude about ICT for remote monitoring (bad as reference) } \\
\hline Good & 1.1261 & 3.4959 & 0.000 & 1.261 & 3.4959 & 0.000 \\
\hline \multicolumn{7}{|c|}{ Self-perceived innovativeness (not innovative as reference) } \\
\hline Innovative & 1.1609 & 3.8048 & 0.000 & 0.8041 & 1.7103 & 0.254 \\
\hline
\end{tabular}

ICT, Information Communication Technology; IT, Information Technology; TM, telemonitoring.

the result is higher than the study in Iran, $20.1 \% .^{20} \mathrm{~A}$ possible explanation may be due to the study period (the study was conducted about 4 years ago).

This survey showed that awareness was significantly associated with computer-related training, technical skill, experience in supporting patients using ICT tools and work experience ( $p$ value $<0.05$ ). Table 3 shows that participants who had good technical skills had a higher awareness in TM (AOR=2.8 (95\% CI.1.1 to 7.1)), implying that participants' technical skills could have a positive correlation with their internet access, usages and availability of infrastructure. This finding is in line with other research studies, which indicate that ICT skills could have increased awareness. ${ }^{23}$

Computer-related training was found to significantly associate with having awareness of TM. Participants who have previous computer-related training were more aware of TM ( $p$ value $=0.021$ ). The possible reason for this could be computer-related training that was more likely to increase participant familiarity in using technologies. ${ }^{21}$

In this survey, the participant's core, engagement and structural readiness were assessed as a proxy to measure overall readiness. About, $65.5 \%$ of participants had low readiness, which indicates there are barriers to successful use of TM among these respondents. ${ }^{19}$ Also, $25.1 \%$ of participants showed an average or moderate readiness towards TM. This result is slightly lower than a study conducted in Nigeria, which reveals $33 \%$ of average readiness. ${ }^{34}$ On the other hand, both results are lower than a study done on Austrian professionals to assess their readiness towards using TM technologies for diabetic patient management and found out $58.2 \%$ of them have average readiness levels. ${ }^{26}$ This might be due to the well-organised infrastructure at the clinical practice site and the availability of technological guidelines promote the use of ICT tools for patient care. Furthermore, only $9.4 \%$ of participants showed high readiness for TM in our survey. This low level of participant readiness is quite distinguishable from the high level of readiness (41\%) among nurses in the USA ${ }^{24}$ This substantial difference could be the result of infrastructural differences and the difference in measurements used in the studies.

In the analysis, ordinal logistic regression was fitted on possible explanatory variables but, due to the violation of 
proportional odds assumption by two explanatory variables, PPOM was fitted, which relaxes the proportional assumption for these two variables. Among all possible explanatory variables fitted into the PPOM, self-perceived innovativeness, attitude towards ICT tools in healthcare, attitude towards remote monitoring, access to a smartphone and computer were significantly associated with TM readiness.

This study showed that participants who owned a personal computer were found to have better readiness in TM. This finding is in line with other studies that indicate a positive correlation between computer access and professionals' readiness. ${ }^{20}{ }^{25}$ According to this study, another important behavioural factor that affects TM readiness was the attitude of participants. Participants who had a favourable attitude towards ICT were 2.4 times more likely to have high readiness compared with participants with an unfavourable attitude towards ICT. This is in line with the findings of a study that found that a positive attitude was related to e-health readiness among healthcare providers.

There are some limitations of the current study that needs to be considered in interpreting the results. The nature of the observational data limits causality from being inferred between the independent and dependent variables. The study was conducted using only a quantitative approach. Future research studies should consider adding a qualitative approach to have more strength in findings. Furthermore, the study is conducted only in teaching hospitals, which may affect the generalisability of the findings to other settings. Future works would be better to incorporate settings other than teaching hospitals.

\section{CONCLUSION}

This study contributes to the existing literature in the following way. We have studied healthcare providers' awareness and readiness towards TM to support diabetes patient management at teaching hospitals in the Amhara region, Ethiopia. In general, Ethiopian healthcare organisations, with the limited resource, are required to provide health services to all populations regardless of where they are, hence, e-Health systems and TM solutions are considered as a potential support to the existing healthcare services or perhaps as an alternative in some healthcare areas such as chronic patient management.

The result indicates that participants have low awareness and readiness level to use TM for managing diabetes patients. There is no major significant difference between physicians and nurses. In regression analysis, it was found that TM awareness is influenced by having computerrelated training, personal computer, technical skills and previous experience of supporting patients using ICT tools, and TM readiness is influenced by attitude about ICT tools, remote monitoring, having smartphone and innovativeness.
Acknowledgements We would like to thank the University of Gondar, for its support during the study. We also thank all data collectors and survey respondents for their contributions.

Contributors BTS, TMY and AYB contributed during the process of proposal development. BTS handled the data collection process. BTS, TMY and AYB were involved during data analysis and write-up. BTS prepared the manuscript and acted as guarantor for the overall content of the article; TMY and AYB provided input into draft of the paper and approved the final draft of the manuscript.

Funding The authors have not declared a specific grant for this research from any funding agency in the public, commercial or not-for-profit sectors.

Competing interests None declared.

Patient consent for publication Not applicable.

Ethics approval Ethical approval to conduct the study was obtained from the ethical review board of the Institute of public health, University of Gondar, Ethiopia (number IPH/837/02/2020). Communication with the different official administrators of each teaching hospital was made through a formal letter obtained from the University of Gondar. The purpose of the study was explained to every participant and their written consent was taken before the study.

Provenance and peer review Not commissioned; externally peer reviewed.

Data availability statement Data are available upon reasonable request. The datasets used and analyzed during the current study are available from the corresponding author on reasonable request.

Supplemental material This content has been supplied by the author(s). It has not been vetted by BMJ Publishing Group Limited (BMJ) and may not have been peer-reviewed. Any opinions or recommendations discussed are solely those of the author(s) and are not endorsed by BMJ. BMJ disclaims all liability and responsibility arising from any reliance placed on the content. Where the content includes any translated material, BMJ does not warrant the accuracy and reliability of the translations (including but not limited to local regulations, clinical guidelines, terminology, drug names and drug dosages), and is not responsible for any error and/or omissions arising from translation and adaptation or otherwise.

Open access This is an open access article distributed in accordance with the Creative Commons Attribution Non Commercial (CC BY-NC 4.0) license, which permits others to distribute, remix, adapt, build upon this work non-commercially, and license their derivative works on different terms, provided the original work is properly cited, appropriate credit is given, any changes made indicated, and the use is non-commercial. See: http://creativecommons.org/licenses/by-nc/4.0/.

ORCID iD

Binyam Tariku Seboka http://orcid.org/0000-0002-8309-5986

\section{REFERENCES}

1 Bashshur RL, Shannon GW, Smith BR, et al. The empirical foundations of telemedicine interventions for chronic disease management. Telemed J E Health 2014;20:769-800.

2 Andrès E, Meyer L, Zulfiqar A-A, et al. Telemonitoring in diabetes: evolution of concepts and technologies, with a focus on results of the more recent studies. J Med Life 2019;12:203-14.

3 EPDF. Dictionary of health information technology and security, 2019. Available: https://epdf.pub/dictionary-of-health-informationtechnology-and-security.html

4 Pressman AR, Kinoshita L, Kirk S, et al. A novel telemonitoring device for improving diabetes control: protocol and results from a randomized clinical trial. Telemed J E Health 2014;20:109-14.

5 Marie A, Chisholm-Burns TLS, Patrick M. Brandon Bookstaver. pharmacotherapy principles and practice. 5th edn. London: McGraw Hill Medical home, 2016.

6 Nathan DM. Diabetes: advances in diagnosis and treatment. JAMA 2015;314:1052-62.

7 International Diabetes Federation (IDF). IDF diabetes atlas Brussels, 2019. Available: https://www.diabetesatlas.org

8 World Health Organization (WHO). The World health report, 2018. Available: https://www.who.int/news-room/fact-sheets/detail/ diabetes

9 Tewahido D, Berhane Y. Self-Care practices among diabetes patients in Addis Ababa: a qualitative study. PLoS One 2017;12:e0169062.

10 Mariye T, Tasew H, Teklay G, et al. Magnitude of diabetes self-care practice and associated factors among type two adult diabetic patients following at public hospitals in central zone, Tigray region, Ethiopia, 2017. BMC Res Notes 2018;11:380. 
11 Heisler M, Bouknight RR, Hayward RA, et al. The relative importance of physician communication, participatory decision making, and patient understanding in diabetes self-management. J Gen Intern Med 2002;17:243-52.

12 Trief PM, Sandberg J, Izquierdo R, et al. Diabetes management assisted by telemedicine: patient perspectives. Telemed J E Health 2008;14:647-55.

13 Hammett J, Sasangohar F, Lawley M. Home Telemonitoring platforms for adults with diabetes mellitus: a narrative review of literature. Proc Hum Factors Ergon Soc Annu Meet 2018;62:508-12

14 Islam SMS, Lechner A, Ferrari U, et al. Mobile phone intervention for increasing adherence to treatment for type 2 diabetes in an urban area of Bangladesh: protocol for a randomized controlled trial. BMC Health Serv Res 2014;14:586.

15 Chase HP, Pearson JA, Wightman C, et al. Modem transmission of glucose values reduces the costs and need for clinic visits. Diabetes Care 2003;26:1475-9.

16 Shane-McWhorter L, McAdam-Marx C, Lenert L, et al. Pharmacistprovided diabetes management and education via a telemonitoring program. J Am Pharm Assoc 2015;55:516-26.

17 Wargny M, Kleinebreil L, Diop SN, et al. SMS-based intervention in type 2 diabetes: clinical trial in Senegal. BMJ Innov 2018;4:142-6.

18 Hossain MA, Quaresma R, Hasan MR, et al. An insight into the bilateral readiness towards telemedicine. Health Technol 2019:9:471-86.

19 Légaré E, Vincent C, Lehoux P, et al. Developing and validating the French-Canadian version of the practitioner and organizational telehealth readiness assessment tools. J Telemed Telecare 2010;16:140-6.

20 Sheikhtaheri A, Sarbaz M, Kimiafar K, et al. Awareness, attitude and readiness of clinical staff towards telemedicine: a study in Mashhad, Iran. Stud Health Technol Inform 2016;228:142-6.

21 Meher SK, Tyagi RS, Chaudhry T. Awareness and attitudes to telemedicine among doctors and patients in India. $J$ Telemed Telecare 2009;15:139-41.

22 Biruk S, Yilma T, Andualem M, et al. Health professionals' readiness to implement electronic medical record system at three hospitals in Ethiopia: a cross sectional study. BMC Med Inform Decis Mak $2014 ; 14: 115$

23 Zayapragassarazan Z, Kumar S, Awareness KS. Awareness, knowledge, attitude and skills of telemedicine among health professional faculty working in teaching hospitals. J Clin Diagn Res 2016;10:Jc01-4.

24 Browning SV, Tullai-McGuinness S, Madigan E, et al. Telehealth: is your staff ready to implement? A descriptive exploratory study of readiness for this technology in home health care. Home Healthc Nurse 2009;27:242-8.

25 Backer TE. Assessing and enhancing readiness for change: implications for technology transfer. NIDA Res Monogr 1995;155:21-41.

26 Muigg D, Kastner P, Duftschmid G, et al. Readiness to use telemonitoring in diabetes care: a cross-sectional study among Austrian practitioners. BMC Med Inform Decis Mak 2019;19:26.

27 Alasmari NM, MohammedAlamri M, et al. Perceptions of Teledentistry among dental professionals in Saudi Arabia. Annals of Tropical Medicine \& Public Health SP182 2019;22.

28 Ajami S, Bagheri-Tadi T. Barriers for adopting electronic health records (EHRs) by physicians. Acta Inform Med 2013;21:129-34

29 van der Zande MM, Gorter RC, Aartman IHA, et al. Adoption and use of digital technologies among general dental practitioners in the Netherlands. PLoS One 2015;10:e0120725.

30 Ayatollahi $\mathrm{H}$, Mirani N, Nazari F, et al. Iranian healthcare professionals' perspectives about factors influencing the use of telemedicine in diabetes management. World $J$ Diabetes 2018;9:92-8.

31 Adenuga KI, lahad NA, Miskon S. Towards reinforcing telemedicine adoption amongst clinicians in Nigeria. Int J Med Inform 2017;104:84-96.

32 Rho MJ, Choi IY, Lee J. Predictive factors of telemedicine service acceptance and behavioral intention of physicians. Int J Med Inform 2014;83:559-71.

33 Nayar P, McFarland KK, Chandak A, et al. Readiness for Teledentistry: validation of a tool for oral health professionals. J Med Syst 2017;41:4.

34 E-Healthcare/Telemedicine readiness assessment of some selected states in Western Nigeria 2012.

35 Williams R. Generalized ordered logit/partial proportional odds models for ordinal dependent variables. Stata J 2006;6:10.1177/1536867X0600600104:58-82.

36 Seboka BT, Yilma TM, Birhanu AY. Factors influencing healthcare providers' attitude and willingness to use information technology in diabetes management. BMC Med Inform Decis Mak 2021;21:10.1186/s12911-021-01398-w. 